\title{
Psychosocial Characteristics of Fathers Who Have Abused Their Children as Seen by Public Health Nurses
}

\author{
Izumi Ueda', Hisako Izumi', Kazuko Saeki², Kyoko Namikawa ${ }^{3}$, Mizue Shiromaru1 \\ ${ }^{1}$ School of Health Sciences, Sapporo Medical University, Sapporo, Japan \\ ${ }^{2}$ Faculty of Health Sciences, Hokkaido University, Sapporo, Japan \\ ${ }^{3}$ School of Health Sciences, Kawasaki University of Medical Welfare, Kurashiki, Japan \\ Email: iueda@sapmed.ac.jp
}

Received 11 July 2014; revised 10 August 2014; accepted 23 August 2014

Copyright (C) 2014 by authors and Scientific Research Publishing Inc.

This work is licensed under the Creative Commons Attribution International License (CC BY). http://creativecommons.org/licenses/by/4.0/

(c) (7) Open Access

\begin{abstract}
This study aims to identify details of the psychosocial characteristics of fathers who have abused children as they appear to public health nurses (PHNs). In this study a qualitative descriptive design was applied to the data analysis. Interviewees were 10 public health nurses (PHNs), in charge of maternal and child health services for 5 or more years at public health centers. The study analyzed 13 cases reported in the PHNs interviews. The characteristics of the fathers who had abused children as seen by the PHNs were the psycho-social characteristics of 'weak suppression and control of impulsiveness', 'cognitive dissonance in the fatherhood role', 'poor social sensitivity', 'unbalanced relationship with other members of the family' and 'weak relationships with people around the father'. The father's impulsiveness and cognitive dissonances in the fatherhood role are associated with weaknesses in the family relationships and social adaptation. Conversely, the weakness in the strength of family relationships and social adaptation affects the father's ability to control impulsiveness and give rise to the cognitive dissonance in the fatherhood role. These in turn interact to create a negative downward spiral, a steadily worsening situation. The findings of this study suggest the necessity for PHNs to focus on the background to the cognitive dissonance in the fatherhood role and to work to educate and guide the fathers.
\end{abstract}

\section{Keywords}

Public Health Nurse, Child Abuse, Father, Psychosocial Characteristics

\section{Introduction}

The $9^{\text {th }}$ report on the "Verification of causes of deaths from child abuse" [1] outlines details of deaths from all

How to cite this paper: Ueda, I., Izumi, H., Saeki, K., Namikawa, K. and Shiromaru, M. (2014) Psychosocial Characteristics of Fathers Who Abused Their Children as Seen by Public Health Nurses. Open Journal of Nursing, 4, 669-675.

http://dx.doi.org/10.4236/ojn.2014.49071 
causes of child abuse. The incidence of deaths of children less than one year of age due to child abuse is the highest (43.1\% of the total), and for children up to two years of age it reaches about $70 \%$. Therefore, early infancy is an especially important time to provide supportive intervention in child abuse cases. Based on the Maternal and Child Health Law of Japan, PHNs at public health departments and public health centers provide maternal and child health services for infants and women in childbirth [2]. This enables PHNs to contribute to prevention of child abuse and be aware of high risk abusive families by practical use of the maternal and child health services. Many previous studies of child abuse cases have focused on mothers and there are only a few that address the characteristics of fathers [3]. However, it is also necessary to provide support by considering the marital relationship while focusing on fathers. The results of the review of the literature on the characteristics of fathers in cases with child abuse and neglect clearly showed the characteristics of the father in child abuse cases to have negative feelings and attitudes towards the family [4]. A preliminary study has the object to describe how public health nurses understand the characteristics of the interpersonal relations and behaviors of fathers who cause child abuse [5].

The main study aims to identify the details of the psychosocial characteristics of fathers who have abused children as seen by public health nurses (PHNs).

\section{Methods}

\subsection{Operational Definitions of Terminology}

\section{1) Child abuse}

There are different definitions of child abuse. The Child Abuse Prevention Law of Japan defines physical abuse such as striking and kicking and sexual abuse of the child, as well as it includes psychological abuse and neglect under the umbrella term "child abuse".

In the study here "child abuse" is defined as physical abuse, psychological abuse, and neglect as stipulated in The Child Abuse Prevention Law. Some studies have reported that the pathology of sexual abuse originates in perpetrator factors, such as the desire for emotional contact, through sexual stimulation [6]. Sexual abuse was excluded from the study here because the pathology of sexual abuse may be seen to differ from the other types of child abuse considered here.

\section{2) Father}

"Father" here refers to either a biological father or to a person viewed as a father of the children, a male who plays the role of father to a child.

\subsection{Design and Sample}

In Prefecture A the study identified a region where social resources such as medical welfare services for children are well established, and requested cooperation in the study at health care centers where permission to approach the personnel had been obtained. At a health care center, we recruited participants (interviewees) from among experienced PHNs, personnel in charge of maternal and child health services at the onset of the study and with at least five years of experience in dealing with child abuse cases. The types of abuse that the participating PHNs would be interviewed about were limited to physical abuse, psychological abuse, neglect, or a combination of these, but no specific identification of the family member instigated in the abuse in the family was indicated. Data were collected from semi-structured interviews based on interview guidelines and were conducted from May to August of 2011. Upon obtaining consent, the narratives were recorded using an IC recorder. The interviewees were requested to recall a father they had assisted in their capacity as a PHN and tell about the case. Each of the interviewees was requested to recall one or two fathers they had assisted in their capacity as PHN and tell about these cases. Interviewees were 10 public health nurses (PHNs), and we analyzed 13 cases reported in the PHNs interviews. All the interviewees talked about the cases while referencing the case records which were available at the interview. The main questions in the interviews were the characteristics of the father and events and the events in the case. The interviews were conducted 1 or 2 times with each interviewee, and lasted an average of about one hour. The interviews were conducted in the work place of the interviewee in a location where privacy could be ensured.

\subsection{Data Analysis}

The data obtained by recording and transcribing the narratives were analyzed by employing a qualitative de- 
scriptive design, and classified by the relevance of a sentence segment or of content that appeared to suggest a matter of importance. Examining the contexts which showed characteristics of the fathers and assigning a coded mark which would not hide the meaning, a coded list of these items was created for each interview. With all the cases to be analyzed, organizing the codes based on similarities, and reviewing the concepts presented by the content of the item, the data were classified into subcategories. Then, identifying similarities in the subcategories and examining the items assigned, each category was assigned a name which was abstracted for the further analysis, enabling identification of core-categories. Finally, the structure of the core-categories established from a comprehension of the background to the category, subcategory, code, and original data.

\subsection{Reliability Assurance}

The validity of the categories was assured by repeated coding and discussion among the co-researchers. For verification of the results, the interviewees were asked to identify variance with the facts or other problems in the extracted categories and subcategories and whether the categories reflected the backgrounds that the core-categories had been developed from.

\subsection{Ethical Considerations}

We obtained approval to conduct the study from the Ethics Committee of Sapporo Medical University. Further, the study was carried out after obtaining informed consent to participate by explaining the outline of the study to the director of the participating health care centers orally and through a letter to request participation in the study. The outline of the study was also explained to the participating PHNs orally and through a letter to request participation in the study, and written consent was obtained prior to the interview. Participants were assured that confidentiality would be maintained at all times, that research findings would not be used for purposes other than the study, and the cases would be sensitively handled and that the anonymity of both PHNs and others involved in the cases would be ensured.

\section{Results}

\subsection{Research Participants and Outline of the Cases}

A total of thirteen cases brought up by the interviewees. All cases arose from neglect by the parents, and involved abuse of a physical or psychological nature (Table 1 ).

Table 1. Outline of cases.

\begin{tabular}{|c|c|c|c|c|c|}
\hline \multirow[t]{2}{*}{ Case } & \multirow[t]{2}{*}{ Husband's Age } & \multirow[t]{2}{*}{ Wife’s Age } & \multicolumn{3}{|c|}{ Type of Child Abuse and Neglect } \\
\hline & & & Physical Abuse & Psychological Abuse & Neglect \\
\hline A & 20 ’s & 20’s & $\circ$ & $\circ$ & $\circ$ \\
\hline B & 20 ’s & 30 ’s & & $\circ$ & $\circ$ \\
\hline $\mathrm{C}$ & 30 ’s & 30 ’s & $\circ$ & $\circ$ & $\circ$ \\
\hline $\mathrm{D}$ & 30 ’s & 20’s & $\circ$ & $\circ$ & $\circ$ \\
\hline $\mathrm{E}$ & 30 ’s & 30 ’s & $\circ$ & & $\circ$ \\
\hline $\mathrm{F}$ & 30 ’s & 30 ’s & $\circ$ & & $\circ$ \\
\hline G & 20’s & 20’s & $\circ$ & $\circ$ & $\circ$ \\
\hline $\mathrm{H}$ & 30 ’s & 30 ’s & & $\circ$ & $\circ$ \\
\hline I & 30 ’s & 40 's & & $\circ$ & $\circ$ \\
\hline $\mathrm{J}$ & 30 ’s & 30 ’s & & $\circ$ & $\circ$ \\
\hline $\mathrm{K}$ & 20's & 10 's & & ○ & ○ \\
\hline $\mathrm{L}$ & 30's & 10 's & & $\circ$ & $\circ$ \\
\hline $\mathrm{M}$ & 40 's & 40 's & & $\circ$ & ○ \\
\hline
\end{tabular}


All the interviewees working at the health care centers were female with an average of 8 years and 6 months (range 6 - 13 years) of experience in dealing with child abuse cases.

The core-categories are expressed with single quotation marks (' '), the categories with double quotation marks (“ ”), and data are with square brackets ([ ]), ( ) shows the Case ID.

\subsection{The Structure on Psychosocial Characteristics of Fathers Who Have Abused Their Children}

The analysis yielded 5 core categories and 10 categories, 22 subcategories, with a 37 final codes. The 5 corecategory were: 'weak suppression and control of impulsiveness', 'cognitive dissonance in the fatherhood role', 'poor social sensitivity', 'unbalanced relationship with other members of the family' and 'weak relationships with people around the father' (Figure 1, Figure 2).

The analysis showed that as seen by the PHNs the characteristics of the fathers who abuse children, including poor restraint on impulsiveness, cognitive dissonance in the fatherhood role, poor social sensitivity, and unbalanced relationships with other members of the family. The father's impulsiveness and cognitive dissonance in the fatherhood role are associated with weaknesses in family relationship building and social adaptation. Conversely, the weakness in family relationship building affects the father's ability to control impulsiveness and give rise to cognitive dissonance in the fatherhood role, and these interact to create a negative downward spiral, a steadily worsening situation. Table 2 shows the details of core categories, categories, and main interview data.

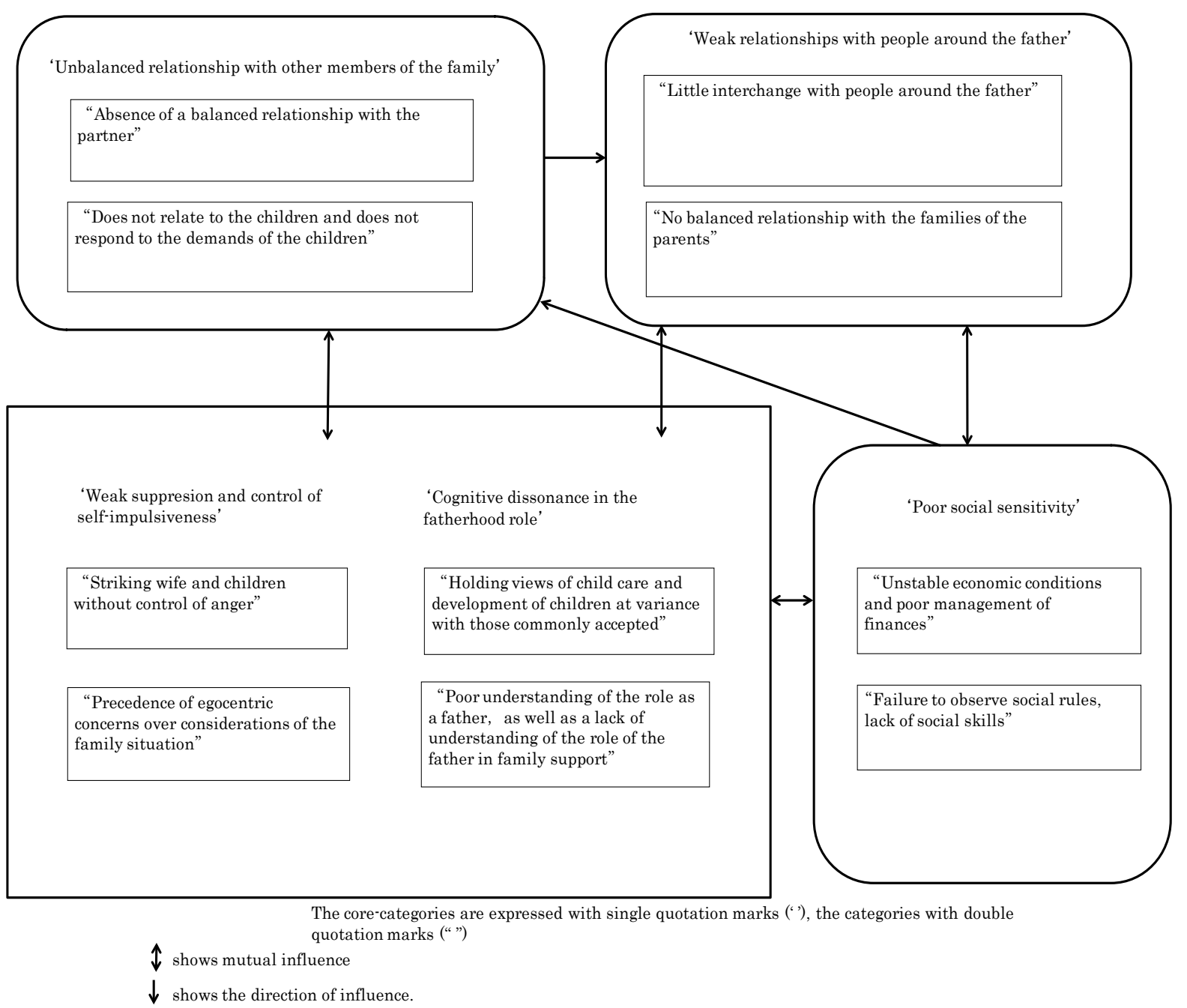

Figure 1. The structure on characteristics of fathers who abused their children from public health nurses’ view point. 


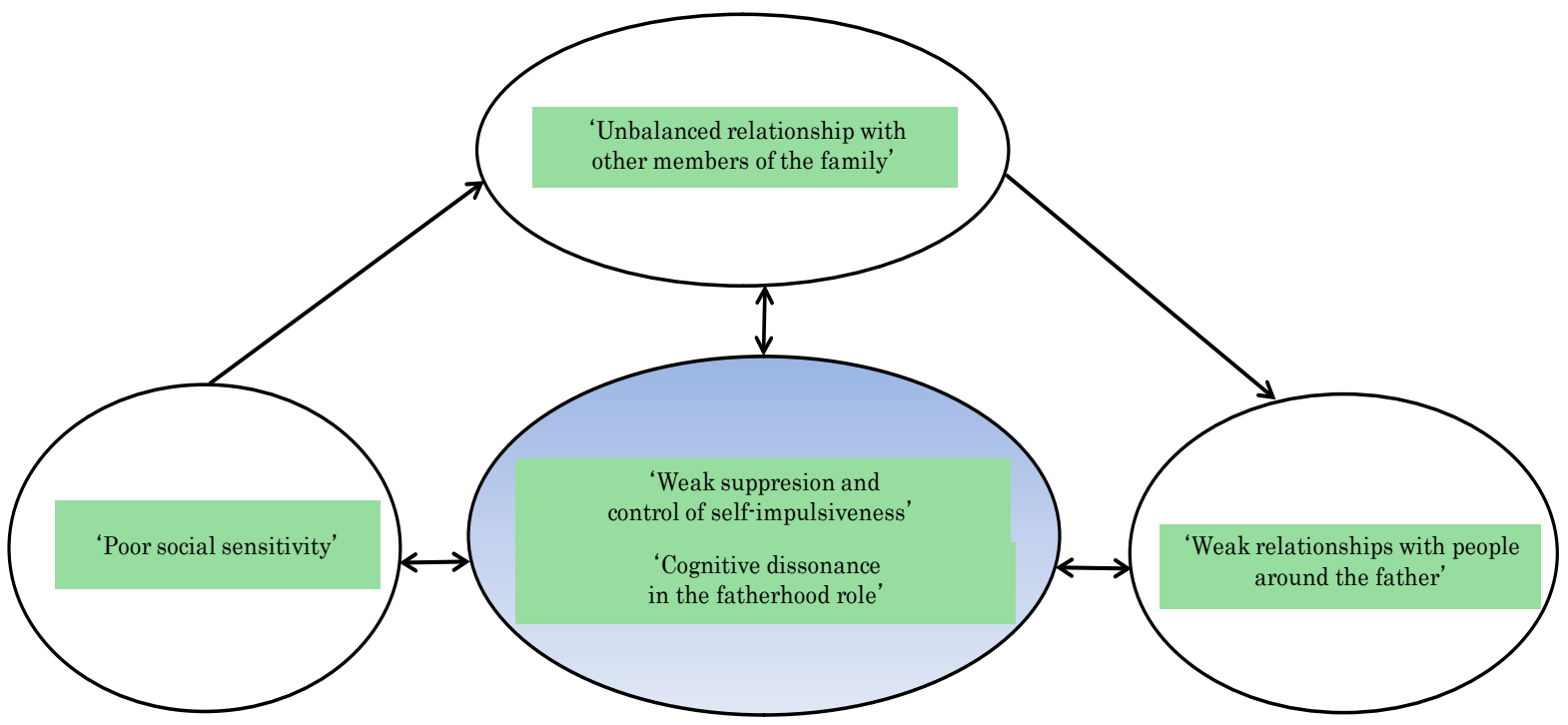

Figure 2. Characteristics of fathers who abused their children from public health nurses' view point.

\section{Discussion}

The core-categories 'Weak suppression and control of impulsiveness' and 'Unbalanced relationship with other members of the family', 'Weak relationships with people around the father', here represent results that were similar to results of the preliminary study carried out by authors [5]. Data in the present study implies that the fathers here are isolated from their families and others by poor relationships with people around the father. The results show the necessity to provide specific education and guidance for the fathers. But, before that there is a need to build relations between PHNs and fathers. It is important to understand the mental background of the fathers, to be able to support the father to become appropriately involved with others.

The core-categories 'cognitive dissonance in the fatherhood role' and 'poor social sensitivity', here represent results that show cognitive dissonance or lack of understanding about child development, methods of child care, and insufficient understanding of the father's roles. The father's poor mental and childcare support of the wife is related to child abuse [7].

Until now the majority of psychosocial characteristics of fathers in Japan have not pointed out that the phenomenon of the father's poor mental and childcare support of the wife as bringing about cognitive dissonance in the fatherhood role. The results of research in the literature and clinical cases have pointed out that father's characteristics were related to domestic violence and alcohol or drug dependency [8].

Further, results of the actual situation on child abuse at one prefecture in Japan [9] have reported that the factors related to the father were most commonly answered with "no particular problem (32.1\%)" and next "uncommon personality (22.8\%)". As mentioned above, it was considered that the father is hard to figure out except in cases of disease or illness. The results obtained in this study are that the psychosocial characteristics of the father of weak suppression and control of impulsiveness and cognitive dissonance in the fatherhood role have not been clearly noted or established by previous studies. It is necessary to understand the mental background to the actions of fathers thinking of reasons for the cognitive dissonance of the father. The father's impulsiveness and cognitive dissonance in the fatherhood role are associated with weaknesses in family relationship building and social adaptation. Conversely, the weakness in family relationship building and social adaptation affects the father's ability to control and suppress impulsiveness and gives rise to cognitive dissonance in the fatherhood role, and these interact to create a negative downward spiral, a steadily worsening condition.

This negative downward spiral shows in the 'Weak suppression and control of impulsiveness', 'Cognitive dissonance in the fatherhood role' and 'Poor social sensitivity' core-categories. A plausible conclusion is that, the father's impulsiveness and cognitive dissonance in the fatherhood role are key points of the psychosocial characteristics of fathers who abuse their children. The finding also suggests that it is important for PHNs to provide support to the mental dimension of fathers for a solution of the father's impulsiveness and cognitive dissonance in the fatherhood role, and it is necessary to squarely face this problem in our modern society. 
Table 2. Details of core categories, categories, and main interview data.

\begin{tabular}{|c|c|c|}
\hline Core categories & Categories & Main interview data \\
\hline \multirow[t]{4}{*}{$\begin{array}{l}\text { Weak suppression and } \\
\text { control of impulsiveness }\end{array}$} & $\begin{array}{l}\text { Striking wife and children } \\
\text { without control of anger }\end{array}$ & $\begin{array}{l}\text { [If the father (he) doesn't get his way, he hits the } \\
\text { children in anger.] (A, C) }\end{array}$ \\
\hline & & $\begin{array}{l}\text { [If quarrels between husband and wife become violently, } \\
\text { he pulls her hair and drags her around.] (G) }\end{array}$ \\
\hline & $\begin{array}{l}\text { Precedence of egocentric } \\
\text { concerns over considerations } \\
\text { of the family situation }\end{array}$ & $\begin{array}{l}\text { [He started to play games as soon as he got home from } \\
\text { work even if the child is screaming, but he told the wife } \\
\text { 'let's play games, together'...] (F) }\end{array}$ \\
\hline & & $\begin{array}{l}\text { [He insists on his wife taking him to and from word and } \\
\text { following his orders even when the wife is pregnant] (B) }\end{array}$ \\
\hline $\begin{array}{l}\text { Cognitive dissonance } \\
\text { in the fatherhood role }\end{array}$ & $\begin{array}{l}\text { "Holding views of child care and } \\
\text { development of children at variance } \\
\text { with those commonly accepted" }\end{array}$ & $\begin{array}{l}\text { [He lifted the child holding the delicate neck of the one } \\
\text { month old baby, and other rough behavior...] (D) }\end{array}$ \\
\hline
\end{tabular}

\section{in the fatherhood role}

Poor social sensitivity

Unbalanced relationship with Absence of a balanced other members of the family relationship with the partner

Weak relationships with people around the father
Unstable economic conditions and poor management of finances

Failure to observe social rules, lack of social skills

Does not relate to the children and does not respond to the demands of the children

Little interchange with people around the father

No balanced relationship with the family of the parents
[He scolded the baby for crying and wetting of diapers.] (C, G)

[Baby was born early; the mother had to go to the health center for many procedures. However she had to do paperwork, leaving the hospital, the father does not assist in any way.] (J)

[Husband's mother said 'I want a grandchild, but I do not want her (the wife)', and the husband did not mentally support the wife.] (I)

[There is no child seat in the car. Children are left lying in the back seat. He does not spend money on anything necessary like food, clothing...] (J)

[I'm afraid he is not honest about money, he earned money by strange work. At that time his income was about 20 thousand a month.] (F)

[Father's occupation was as a guard man. But, he resigned because of lower back pain. He always stays in his house as he has lower back pain and asthma.] (G)

[Father does not pay when eating out. In addition, he threatens others. The basic reason is that he can't keep the common social rules.] (D)

[They quarrel almost every day. The children worry if the mother is all right.] (L)

[Mental health of the wife became poor because of his vague attitudes. He had refused divorce from his wife, but, they filed for divorce.] (M)

[Father hit children because of interference with a game he is playing.] $(\mathrm{E}, \mathrm{H})$

[He pays attention to only the biological child among several brothers. But he cares for the child when in a good mood, but when in a bad mood... he does not take care of the child.] (B)

[Because father has an aggressive manner in the nursery school, people could not approach the father. He does nothing but complain from morning till night. The people around the father avoid him.] (A)

[I have not heard that there is any relationship with the people around the father.] (I, L)

[The family of younger brother lives in the neighborhood, but when they are visiting will not let children play at all.] (K)

[The parents of father lives near the home. But there is no relationship at all. The parents of mother lives near the home, but they cannot be asked to support.] (E, J) 


\section{Conclusions}

The central finding in this study is the structure which shows that the psychosocial characteristics of the father who abused their children from PHNs' view point.

It is necessary to understand the mental background to the actions of fathers, such as the sense of values and emotions hidden behind the superficial behavior. In addition, it is important to specifically provide education and guidance on the father roles to make it possible for the fathers to show sufficient responsibility.

A research-based structural understanding of the psychosocial characteristics of the father has not been established. The new knowledge obtained in this study is that the structure of the psychosocial characteristics of the father involving weakness in the suppression and control of impulsiveness and cognitive dissonance in the fatherhood role influences human relations including family relationships, and that these are also influenced by poor social sensitivity.

\section{Limitations}

The present study has the following limitations: we addressed only cases that were dealt with by PHNs who worked in public health centers. The characteristics of the fathers were not characteristics reported by the fathers themselves or others involved, but the characteristics perceived by the PHNs.

\section{Acknowledgements}

The research team expresses thanks to the participants for accepting to be interviewed and making room in their busy schedules.

\section{References}

[1] Committee on Council of Social Security of Children Se-Ction Concering Child Abuse (2013) The 9's Analysis Reports by Death Cases of Child Abuse and Neglect. Ministry of Health, Labor and Welfare. http://www.mhlw.go.jp/stf/houdou/2r98520000037b58-att/2r98520000037bag.pdf

[2] Izumi, U. and Kazuko, S. (2009) 6-1 Public Health Nurse’s Care for Mather and Child Health, New Child Care for Neighborhood Action. Chuuouhoukisyuppan Press, Tokyo, 224-231.

[3] Cindy, M., Pamela, C., Kimberly, B., et al. (2005) Predicators of Child Abuse Potential among Military Parents: Comparing mothers and Fathers. Journal of Family Violence, 20, 123-129. http://dx.doi.org/10.1007/s10896-005-3175-6

[4] Izumi, U., Kazuko, S., Mariko, K., et al. (2010) Reviews of Domestic and International Research Papers on the Characteristics of Fathers Regarding Child Abuse. Japanese Journal of Child Abuse \& Neglect, 12, 271-287.

[5] Izumi, U., Kazuko, S., Mariko, K., et al. (2014) A Perspective of Public Health Nurses on the Human Relations and Behavioral Characteristics of Fathers Who Abused Their Children. Japanese Journal of Public health Nursing, 2, 2-11.

[6] Yuri, M. (2008) Sexual Abuse to Children. Iwanamisyoten Press, Tokyo, 32-52.

[7] Micyiko, K. (1999) Chapter III Support for Child Abuse and Neglect, The Detection and Check on Child Abuse and Neglect. Tokisyobou, Oosaka, 140-158.

[8] Takeshi, T. (2007) Psychoeducational Approaches for Families: Concept and Methods: Approaches for Fathers Group. Kanekosyobou Press, Tokyo, 59-73.

[9] Department of Health and Welfare, Metropolis of Tokyo (2007) The 2nd Report on the Actual Situation of Child Abuse. http://www.mhlw.go.jp/bunya/kodomo/dv36/index.html 
Scientific Research Publishing (SCIRP) is one of the largest Open Access journal publishers. It is currently publishing more than 200 open access, online, peer-reviewed journals covering a wide range of academic disciplines. SCIRP serves the worldwide academic communities and contributes to the progress and application of science with its publication.

Other selected journals from SCIRP are listed as below. Submit your manuscript to us via either submit@scirp.org or Online Submission Portal.
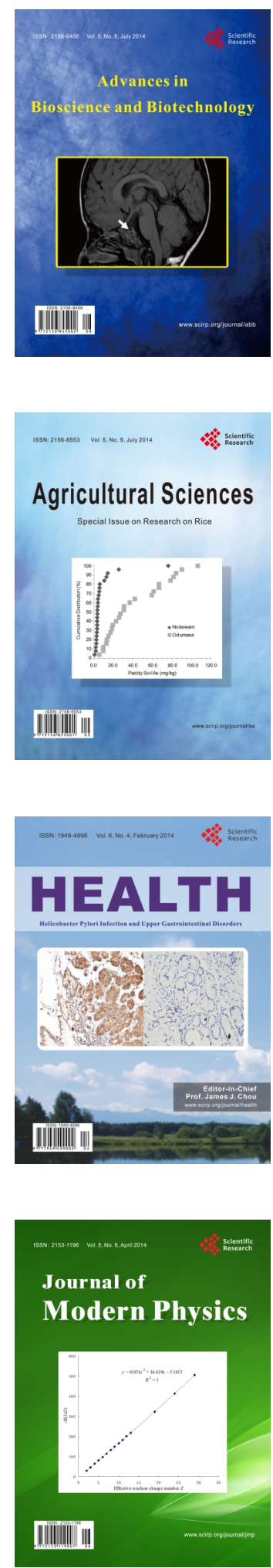
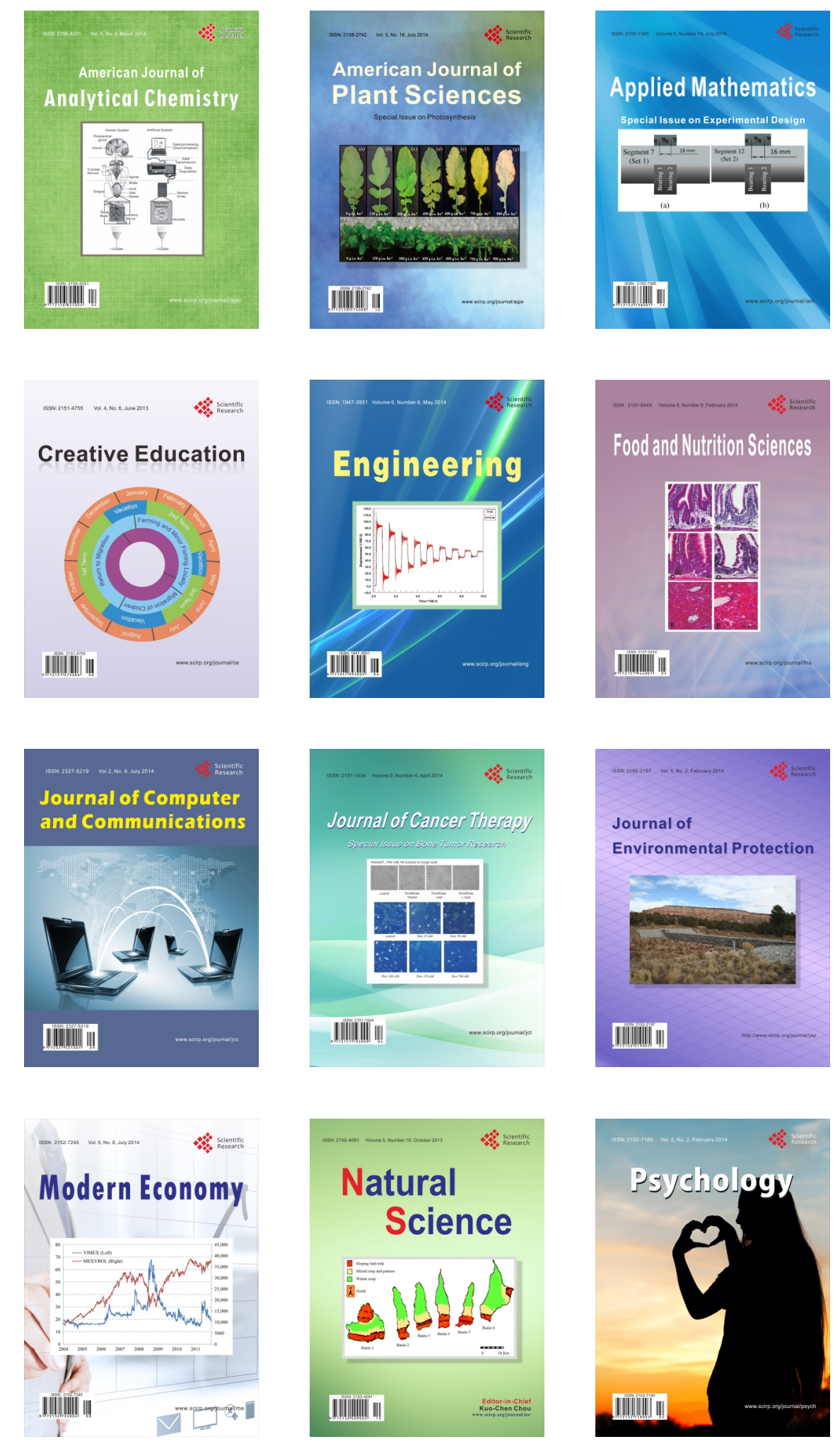